\title{
Itinerario de retablos rococó en La Orotava, Tenerife. Policromía del retablo de San Miguel
}

\section{Carmen Suárez Benitez ${ }^{\mathrm{a}}$}

${ }^{a}$ Doctoranda en Arte y Humanidades en la Universidad de La Laguna, 38300, La Laguna. carmensuarezb@gmail.com.

\begin{abstract}
Resumen
La Villa de La Orotava es un municipio con un Patrimonio retablístico que data desde el S. XVI hasta la actualidad. Mediante la ruta propuesta se persigue la divulgación de aquellos de finales del S.XVIII de propiedad eclesiástica, para hacer énfasis en la Policromía, rica por la variedad de sus motivos, así como por los recursos polícromos utilizados para generar "efectos volumétricos". Se pretende así, acercar a los visitantes las características propias del Rococó en Tenerife.
\end{abstract}

Palabras clave: patrimonio retablístico, La Orotava, itinerario, retablos rococó, policromía, retablo de San Miguel, Tenerife.

\footnotetext{
Abstract

La Orotava is a town with an Altarpiece's Heritage dating from the 16th century to the present. Through the proposed route, we want to put a spotlight on those from the end of 18th century of ecclesiastical property, to highlight their polychromy, which vibrates with a variety of motifs, as well as for the polychrome resources used to create "volumetric effects". It is our aim to expose visitors to "the Rococo features" in Tenerife.
}

Keywords: altarpiece's heritage, La Orotava, route, rococo's altarpieces, polychrome, San Miguel's altarpiece, Tenerife. 


\section{Introducción}

La Villa de La Orotava es un municipio situado en el Valle del mismo nombre en el norte de la isla de Tenerife. Abierta al mar y coronada por el Teide (a 3718 metros), cuenta con numerosos Espacios Naturales Protegidos ${ }^{1}$ (Fig. 1).

Con una población de 41.833 habitantes $^{2}$, su economía básica está centrada en la agricultura y servicios. El municipio se divide en 23 entidades de población, siendo "La Orotava" la capital municipal. En ella se concentran el mayor número de habitantes y, localizamos además el casco histórico.

Este último, declarado Conjunto Histórico Artístico en 1976, se encuentra casi enteramente intacto. Presenta edificios de gran interés patrimonial como la Casa Consistorial, casas tradicionales con balcones típicos de madera, plazas, antiguos conventos,

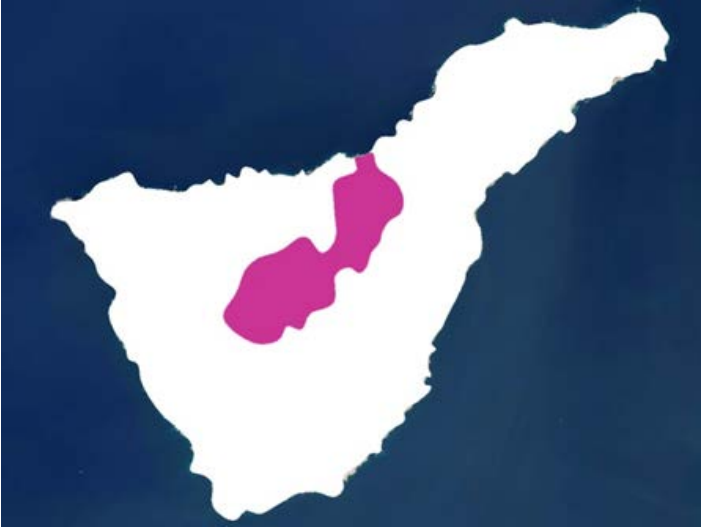

Fig. 1 Localización del Valle de La Orotava en la isla de Tenerife templos, etc. (Fig. 2).

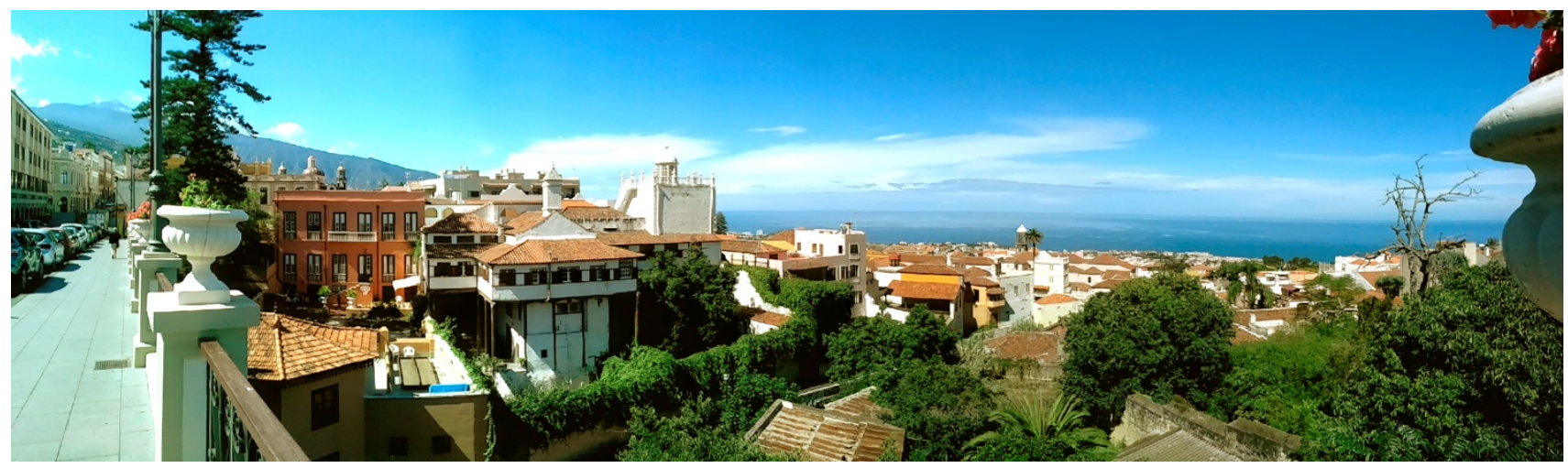

Fig. 2 Panorámica en la que se aprecia parte del Casco Histórico de La Orotava

Conserva un Patrimonio retablístico de cuarenta y dos retablos que datan desde el S. XVI hasta nuestros días. Su propiedad es tanto eclesiástica -se ubican en templos, parroquias y ermitas- como particular- se localizan en ermitas o en casas particulares-. Trece de ellos, son del S. XVIII ${ }^{3}$, de los cuales, nueve son de estilo rococó -cinco de propiedad eclesiástica y cuatro de propiedad particular-.

\section{Desarrollo temático}

\subsection{Itinerario Propuesto}

El itinerario que proponemos consiste en visitar los cinco retablos rococó de propiedad eclesiástica ubicados en la Villa de La Orotava. Realizados a finales del S. XVIII, son retablos conocidos como retablos de pintura, debido a presentar talla solo en los tramos de molduras. Importantes por la riqueza de sus policromías en cuanto a la variedad de motivos y recursos volumétricos encontrados, nos permiten entender las características de las policromías rococó de la isla.

\footnotetext{
1 Parque Nacional del Teide, Parque Natural de la Corona Forestal, Reserva Natural de Pinoleris y el Paisaje Protegido de la Resbala. https://www.webtenerife.com/tenerife/la-isla/municipios/orotava/?tab=1 (Consulta el 30 de octubre de 2019).

${ }^{2}$ Según datos publicados por el INE a 1 de enero de 2018. https://www.foro-ciudad.com/tenerife/la-orotava/habitantes.html (Consulta el 30 de octubre de 2019).

${ }^{3}$ Debido, entre otras razones, a la próspera economía local gracias al comercio del vino en Europa (Arbelo, 2005, pp. 187-188).
} 


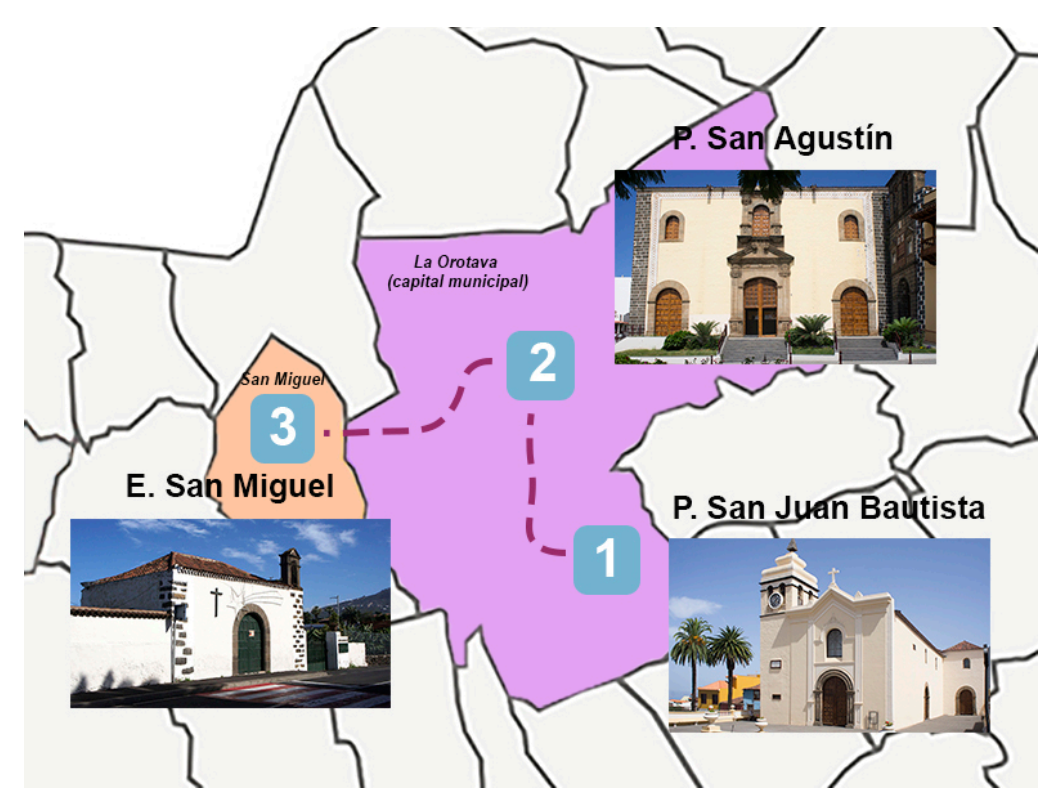

Fig. 3 Plano de localización de las Parroquias y Ermita en sus respectivas entidades. En violeta "La Orotava" (capital municipal) y en naranja "San Miguel"

El recorrido lo establecemos teniendo en cuenta dos factores. Por un lado, la cronología del templo, por tanto comenzaremos por el más antiguo. Por otro, la accesibilidad de los visitantes ya que, debido a la orografía de fuerte pendiente del municipio, se realizará un recorrido descendente. Las arquitecturas se encuentran ubicadas en:

- $\quad \mathrm{N}^{0}$ 1. Parroquia de San Juan Bautista. Entidad "La Orotava” (capital municipal) (Fig. 3)

- $\quad \mathrm{N}^{\mathrm{o}}$ 2. Parroquia de San Agustín. Entidad "La Orotava” (capital municipal) (Fig. 3)

Por último en la entidad "San Miguel":

- $\quad \mathrm{N}^{0}$ 3. Ermita de San Miguel. Entidad "San Miguel” (Fig. 3)

Comenzaremos visitando la Parroquia de San Juan Bautista (S. XVII) - Fig. 4-. En ella encontramos el Retablo del Señor de la Cañita, el Retablo de la Virgen de los Remedios y el Retablo de San Juan Bautista (Figs. 5, 6, 7 y 8).

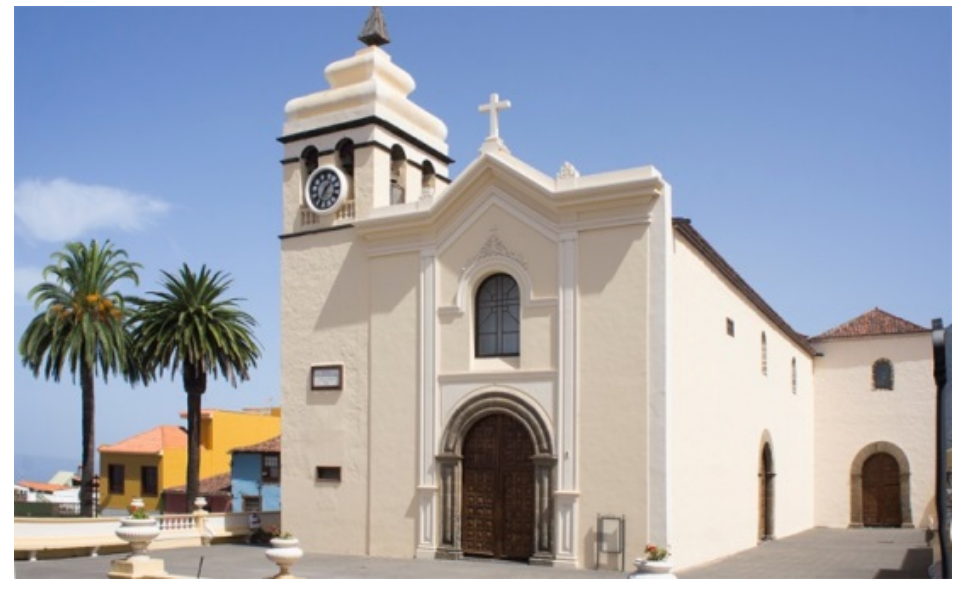

Fig. 4 Parroquia de San Juan Bautista

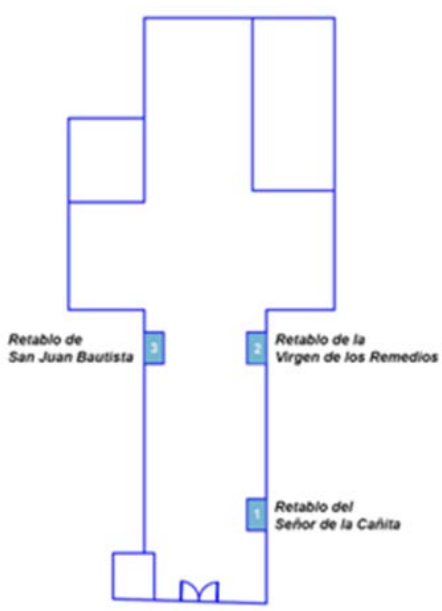

Fig. 5 Planta de cruz latina a escala. Localizamos los tres retablos en la nave central 
Son retablos realizados en madera, dorados y policromados. Su estructura obedece a un sistema constructivo de caja arquitectónica, con planta rectilínea. Las tres arquitecturas se encuentran restauradas, los dos primeros por el D. Marcos Hernández Moreno en los años 2007 y 2009 respectivamente, y el tercero por Dña. Candelaria García Díaz en 2019.

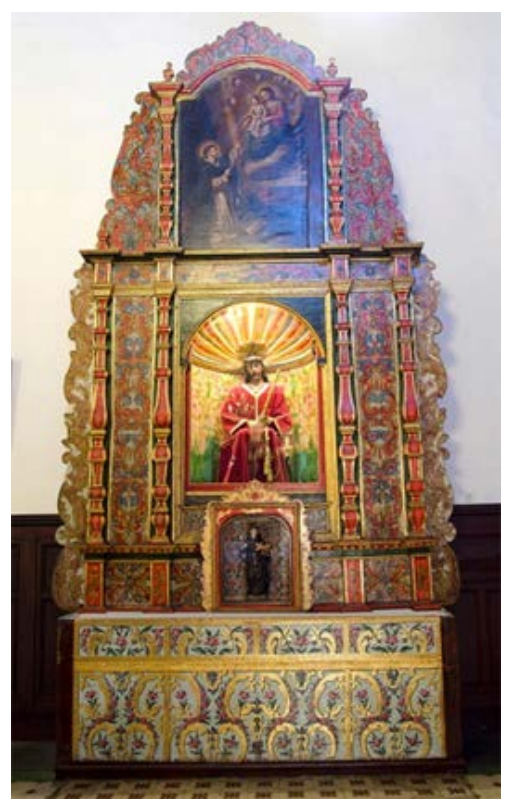

Fig. 6 Retablo del Señor de la Cañita

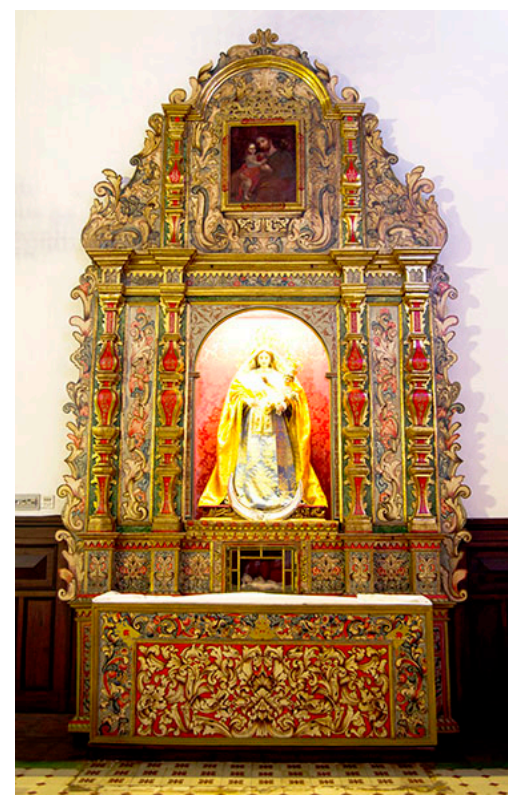

Fig.7 Retablo de la Virgen de los Remedios

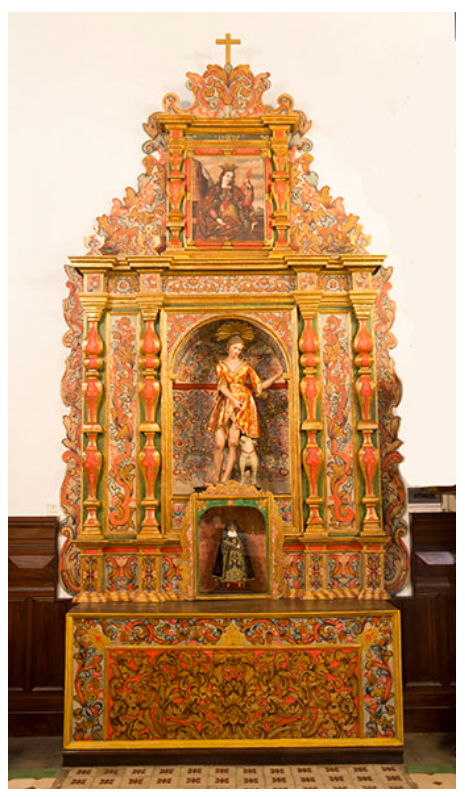

Fig. 8 Retablo de San Juan Bautista

A continuación, nos trasladaremos a la Parroquia de San Agustín (S. XVII) (Fig. 9), donde localizamos el Retablo de la Humildad y Paciencia en la primera capilla colateral del lado del Evangelio (Fig. 10). Realizado también en madera, se encuentra dorado y policromado (Fig. 11). Su estructura obedece a un sistema constructivo de caja arquitectónica con planta poligonal. No ha sido restaurado.

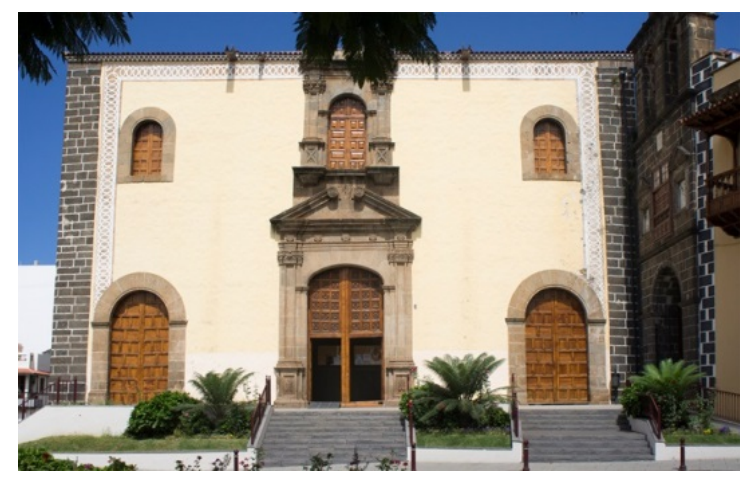

Fig. 9 Parroquia de San Agustín

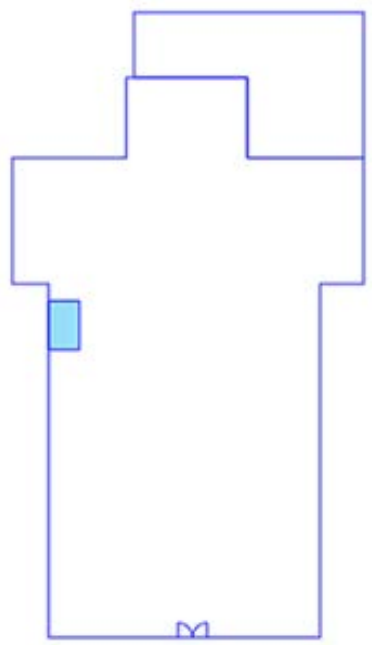

Fig. 10 Planta a escala y ubicación del retablo

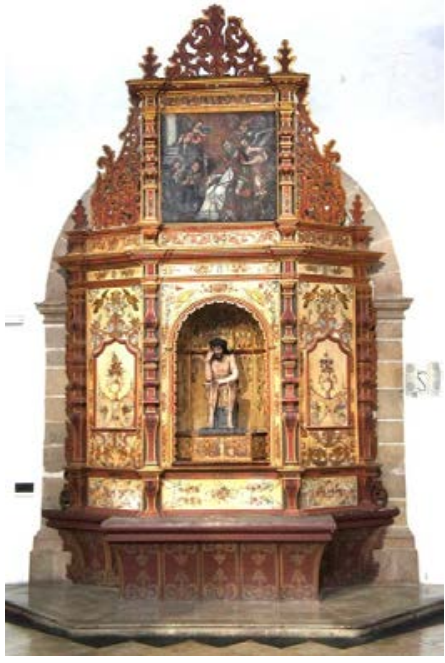

Fig. 11 Retablo de la Humildad y Paciencia

Por último, en la entidad San Miguel, visitaremos la Ermita y Retablo de San Miguel (Fig. 12 y Fig. 13). Esta arquitectura está realizada en madera policromada. Su sistema constructivo es de caja arquitectónica y, al igual que el anterior, su planta es poligonal. Fue intervenido por D. Fernando Weyler y López de Puga, aproximadamente en el año 1994 (Fig. 14). 


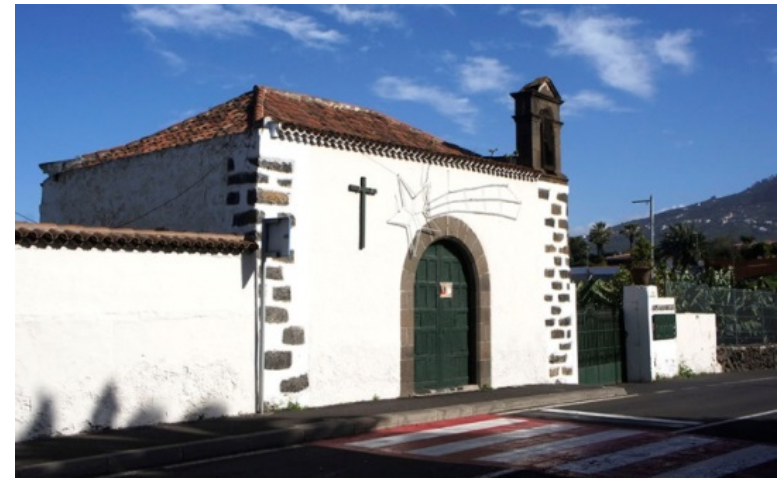

Fig. 12 Ermita de San Miguel

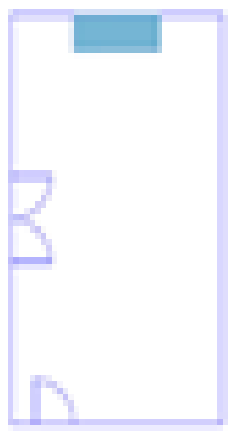

Fig. 13 Planta a escala $y$ ubicacion del retablo

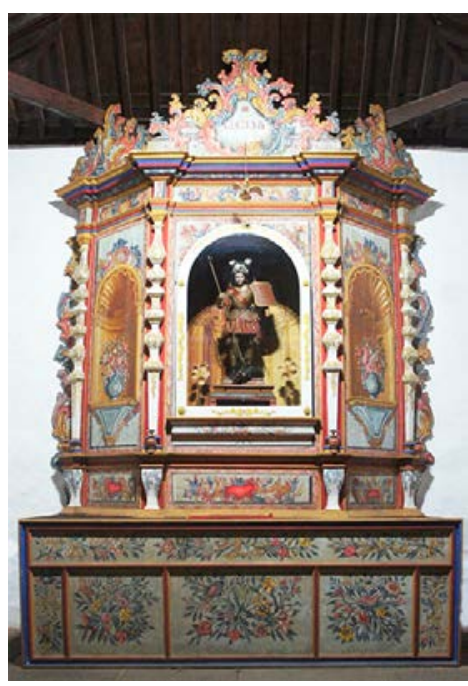

Fig. 14 Retablo de San Miguel

Como podemos apreciar, todos obedecen a una misma composición, retablos de un cuerpo y hornacina en la calle central. Cuatro de ellos cuentan con ático y coronación, encontrando ésta última únicamente en el restante. Presentan un sistema constructivo de caja arquitectónica, es decir, precisan de una estructura sólida adosada al muro para servir de apoyo al conjunto de tablas independientes que forman su mazonería (Tudela, 2005). Este tipo de retablos son eminentemente planos, con volúmenes definidos por los recursos cromáticos, por los tableros recortados y, además, por los tramos de molduras.

La autoría de todos ellos se desconoce. Sin embargo, se le atribuye al pintor Cristóbal Afonso (1742 - 1797), las policromías del Retablo de la Virgen de los Remedios, Retablo de San Juan Bautista (Fig. 7 y Fig. 8), ambos en la Parroquia de San Juan Bautista (Lorenzo, 2008) y del Retablo de San Miguel (Fig. 13) debido a la semejanza de sus repertorios con los realizados por el mismo.

Como se comentó con anterioridad, estos retablos de pintura, presentan una policromía de motivos variados y de recursos polícromos. Su estudio se ha organizado de lo general a lo particular, utilizando la siguiente terminología:

- Temática: Elemento que representa un motivo.

- Denominación: Cada uno de los grupos de los que se compone la temática.

- Tipología formal: Forma en la que se representa y organizan los motivos.

Las ocho Temáticas, Denominaciones y Tipologías Formales de los motivos localizadas en el Retablo del Señor de la Cañita, Retablo de la Virgen de los Remedios, Retablo de San Juan Bautista y Retablo del Señor de la Humildad y Paciencia, se encuentran detalladas en -Tabla 1-. Posteriormente, nos detendremos en la policromía del Retablo de San Miguel, donde realizaremos una descripción más pormenorizada.

\subsection{Policromía del retablo de San Miguel}

En la entidad de población "San Miguel”, encontramos la Finca y Ermita de San Miguel, templo ubicado en el Camino de La Luz, como parte del mayorazgo fundado en el S. XVI por el capitán y regidor Miguel de Franchi y su esposa, Elvira de Alfaro y Figueroa (Luque, 1998) (Figs. 15 y 16).

El Retablo de San Miguel se ubica en la capilla mayor de la única nave. Realizado en madera, se encuentra policromado en su totalidad. El conjunto presenta tres calles y descansa sobre el altar. De planta poligonal con desarrollo en avance en la calle central, encontramos una hornacina con la imagen titular. Los cuatro estípites del primer cuerpo, aportan mayor superficie de apoyo al conjunto y nacen del banco en forma de pedestales. Se encuentra rematados en los laterales y en la parte superior por una coronación -presente en las tres calles- de tableros recortados (Fig. 17). 
Tabla 1. Temáticas, Denominaciones y Tipologías Formales de los motivos de la policromía de cuatro retablos

\begin{tabular}{lll}
\hline \multicolumn{1}{c}{ Temática } & \multicolumn{1}{c}{ Denominaciones } & \multicolumn{1}{c}{ Tipología Formal } \\
\hline - Motivos Vegetales & - Follajes de Acanto. & - Composiciones Simétricas. \\
& - Motivos Florales. & - Cenefas. \\
& & - Ramos y Ramilletes. \\
& - Composiciones Simétricas. \\
-Imitaciones de materiales Pétreos. & - En Jarrones. \\
& - Retícula. \\
- Rocallas. & - Líneas. \\
- Cartelas. & - Manchas. \\
- Medallones. & - Trama. \\
- Efectos Volumétricos. & - Composiciones Simétricas. \\
& - Composiciones Simétricas. \\
- Aves. & - Sombreados. & - Composiciones Simétricas. \\
- Imitaciones Asimétricas. \\
\hline
\end{tabular}

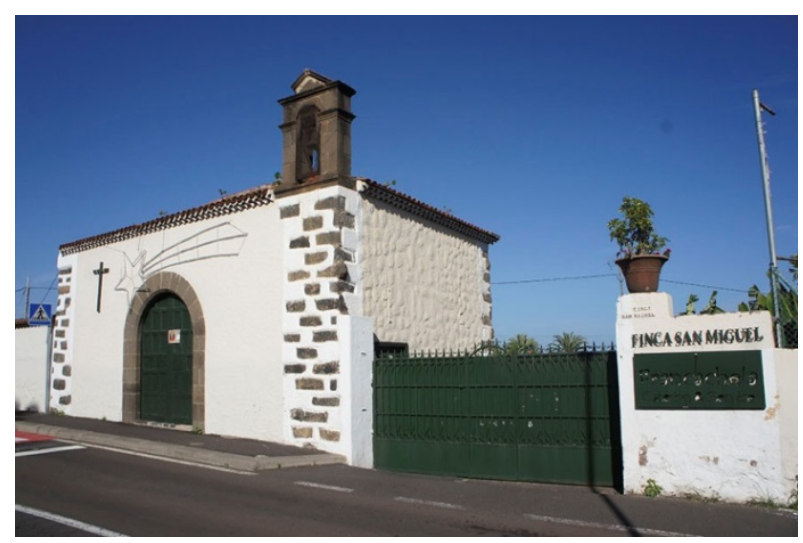

Fig. 15 Ermita y Finca de San Miguel. De planta rectangular, mide 9,30 $\mathrm{m}$ de largo por 5,30 $\mathrm{m}$ de ancho. Es un edificio de piedra y techo de cuatro aguas con tejas. Presenta dos entradas, una desde la finca y otra desde la calle

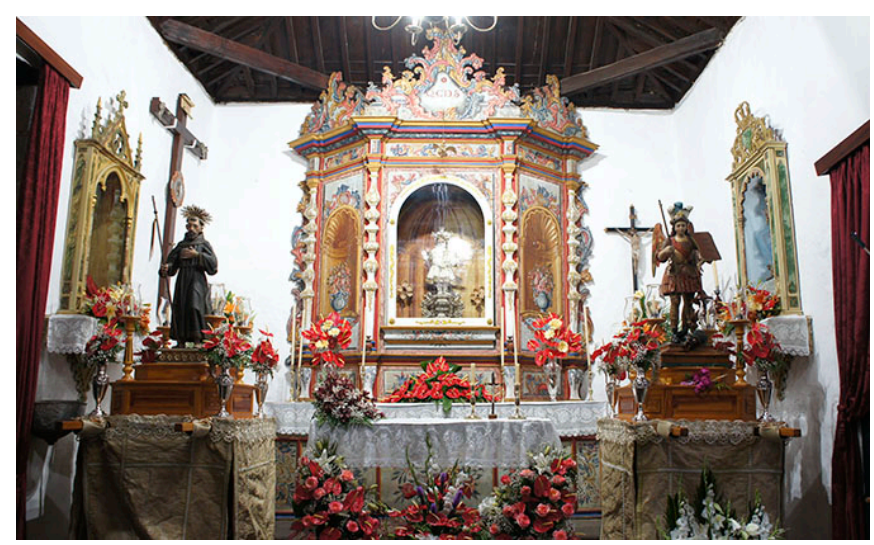

Fig. 16 Interior de la Ermita. Vemos a San Francisco y a San Miguel en sus tronos habituales debido a la festividad del último, el día 29 de septiembre

Como se dijo con anterioridad, la policromía se atribuye al pintor Cristóbal Afonso (Luque, 1998). Realizada una vez asentado el retablo, los motivos se distribuyen simétricamente en torno al completo de la arquitectura, encontrando no obstante, diferencias de dibujo y color entre conjuntos. De las ocho Temáticas de los motivos señaladas en -Tabla 1-, en este retablo aparecen siete, distribuidas según Gráfico 1.

Las Tipologías Formales en las que se representan los motivos, son varias. Las Composiciones Asimétricas son las que encontramos en mayor número. Sin embargo, también observamos Ramilletes, Ramas, Líneas, Fundidos y Planos de color como veremos desglosadas por apartados según la temática a continuación.

- Los Motivos Vegetales son los más abundantes, encontrando las dos Denominaciones en las que se subdivide: Follajes de Acanto y Motivos Florales, las cuales vemos distribuidas en Gráfico 2.

- Los Follajes de Acanto aparecen en dos Tipologías Tormales. En forma de Ramas en los remates laterales (Fig. 18) y organizadas en Composiciones Asimétricas en los estípites y en la coronación de las calles laterales (Figs. 19 y 20). 


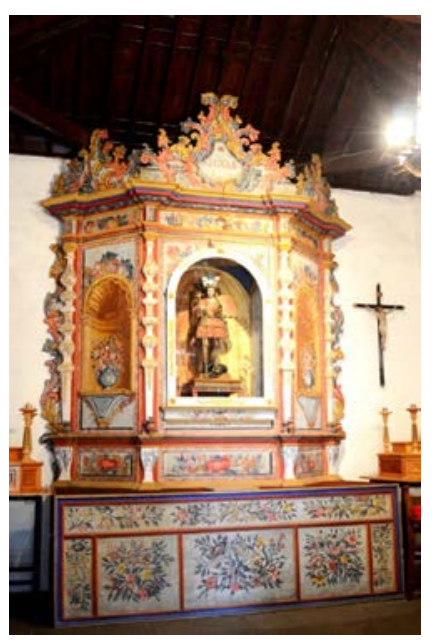

Fig. 17 Retablo de San Miguel
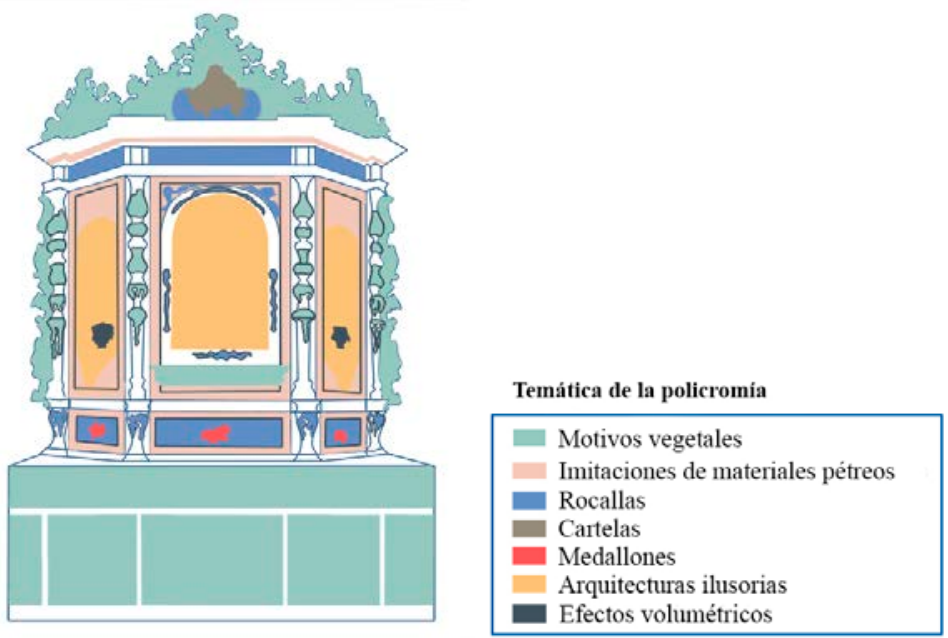

Gráfico 1. Distribución de las Temáticas en el retablo

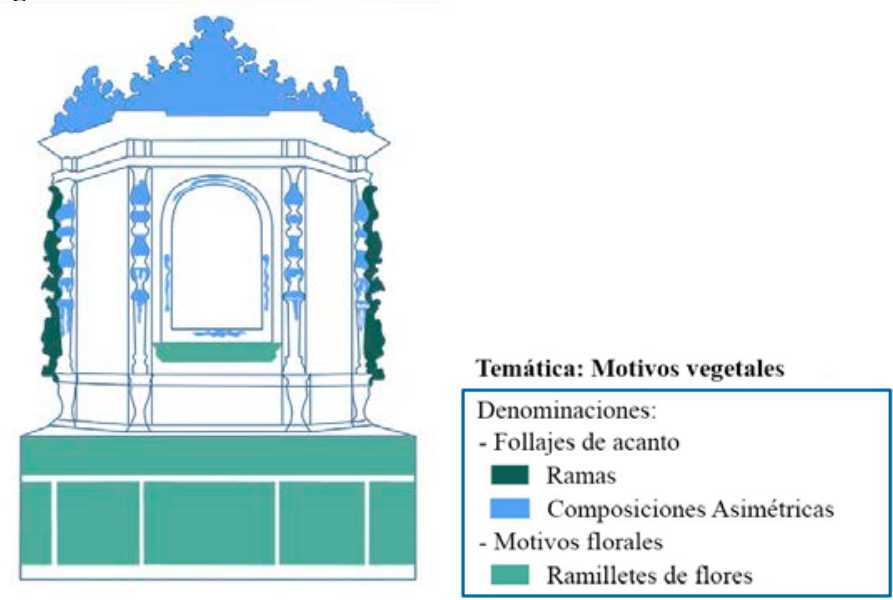

Gráfico 2. Distribución de las Denominaciones y Tipologías Formales de los motivos vegetales

- Los Motivos Florales, aparecen en forma de Ramilletes, encontrándose distribuidas en el frontal del altar (Fig. 21) y en la repisa inferior de la hornacina (Fig. 22). tal y como vemos en el Gráfico 1 y 2.

- Las Imitaciones de Materiales Pétreos es otra Temática encontrada. Localizamos un total de cuatro jaspeados distintos, en forma de Líneas (Figs. 23, 24 y 25).

- La siguiente Temática son las Rocallas, localizadas formando Composiciones Asimétricas en los pedestales (Fig. 26), bancos de las tres calles (Fig. 28), enjutas y entablamentos (Fig. 25).

- Las Cartelas es la Temática formada por Follajes de Acanto y Rocallas presentada en forma de Composición Asimétrica en la c oronación de la calle central (Fig. 27).

- Los Medallones es la Temática localizada en el banco de las tres calles. Aparecen como motivo central formando Composiciones Asimétricas, sin obedecer a una simetría (Fig. 28).

- Arquitecturas ilusorias es otra Temática ubicada en diferentes partes del retablo, presentes en las calles laterales e interior de la hornacina (Figs. 29, 30 y 31 ).

- La última Temática localizada en la policromía de este retablo son los Efectos Volumétricos, también denominados Sombreados, resueltos mediante tres diferentes Tipologías Formales -Gráfico 3 y Figs. 32 y 33-.

- Planos de color es la última tipología integrante de esta Temática. Nos referimos a aquellas manchas utilizadas a modo de azulejos que, mediante la técnica del claroscuro generan relieves (Figs. 23 y 28). 


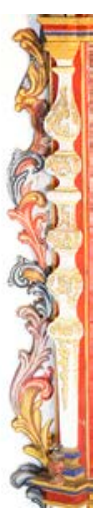

Fig. 18 Rama de Follajes de Acanto. La ubicamos en el remate del lado del Evangelio. Aparece serpenteante y muestra diferentes colores

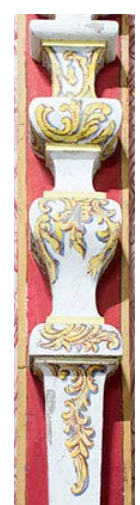

Fig. 19 Composiciones Asimétricas de Follajes de Acanto en los estípites

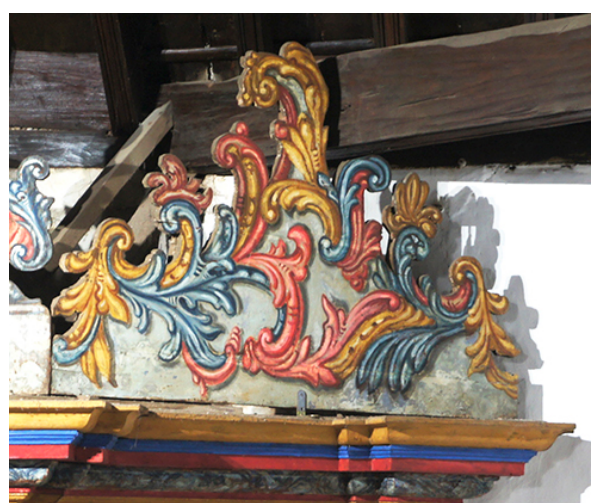

Fig. 20 Composición Asimétrica de Follajes de Acanto localizadas en la coronación del lado de la Epístola

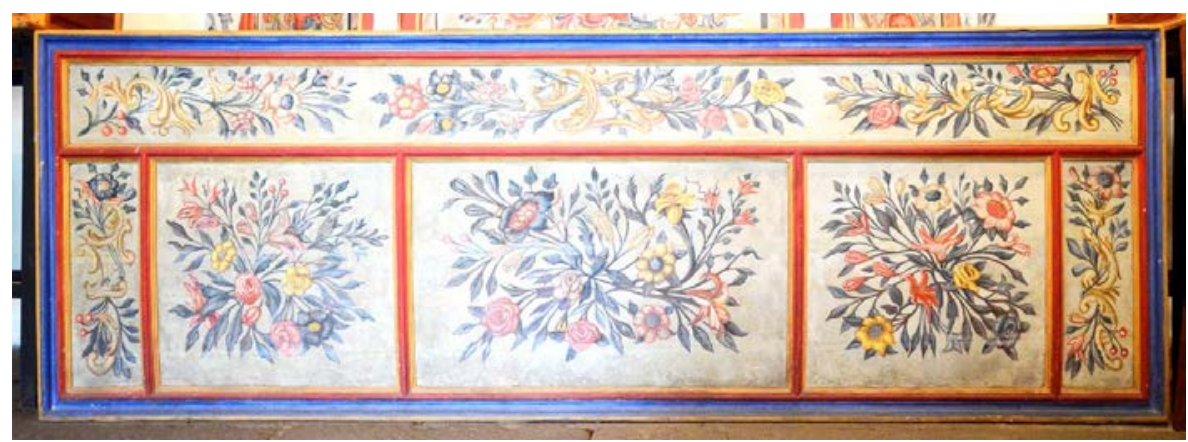

Fig. 21 Ramilletes del frontal del altar. Apreciamos ocho: tres centrales, dos verticales en los extremos y tres de orientación horizontal en la banda superior, separados por molduras. Su dibujo es distinto, siendo similares los colores utilizados

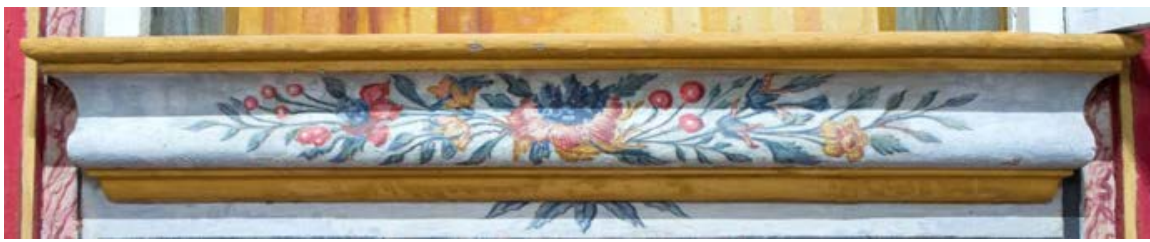

Fig. 22 Ramillete de flores y frutos en el centro de la repisa de la hornacina

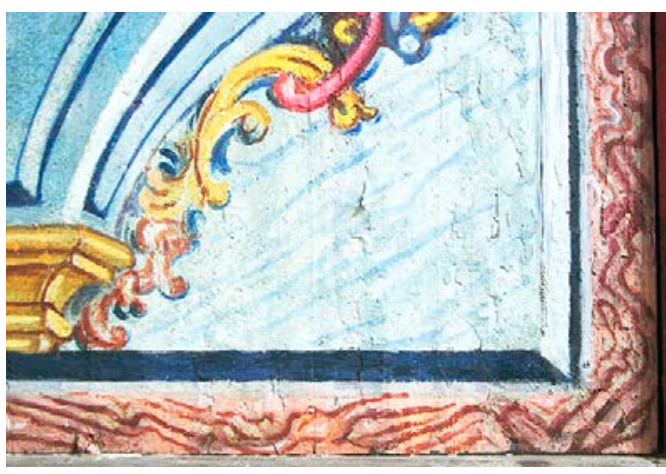

Fig. 23 Jaspeado de líneas irregulares con orientación diagonal utilizado como fondo en las calles del retablo. También observamos un Jaspeado con líneas largas y curvas de tonos magentas a modo de ribete en las calles y bancos. Apreciamos por último, un Efecto Volumétrico en Planos de Color

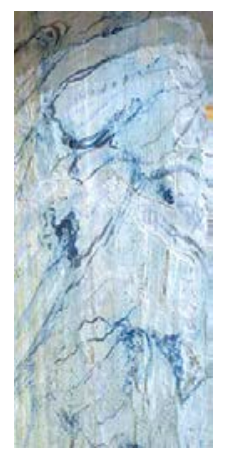

Fig. 24 Jaspeado de líneas curvas e irregulares localizado en los tableros laterales de la hornacina 


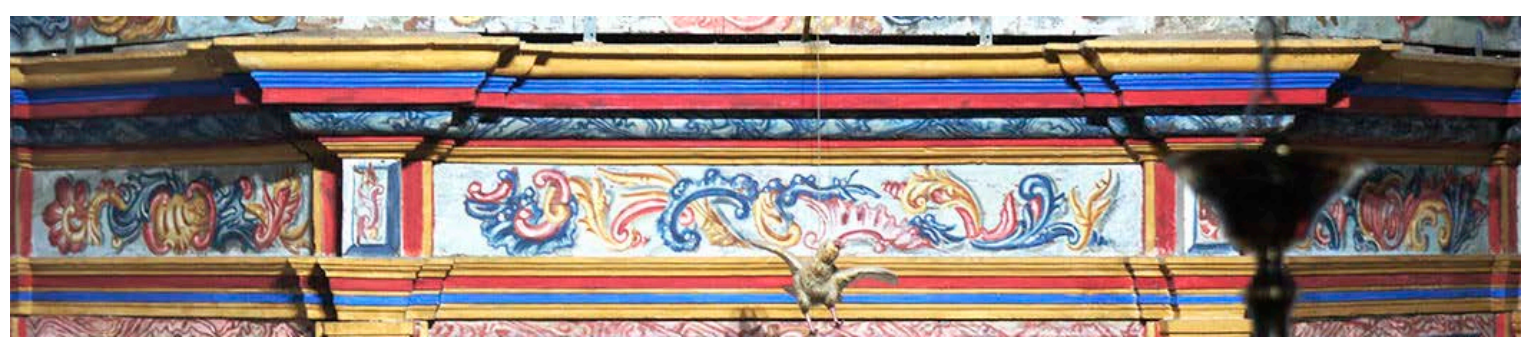

Fig. 25 Jaspeado de líneas curvas e irregulares que se entrecruzan en la cornisa del entablamento, correspondiente al último jaspeado. Apreciamos también, Composiciones Asimétricas de rocallas en el entablamento de las tres calles

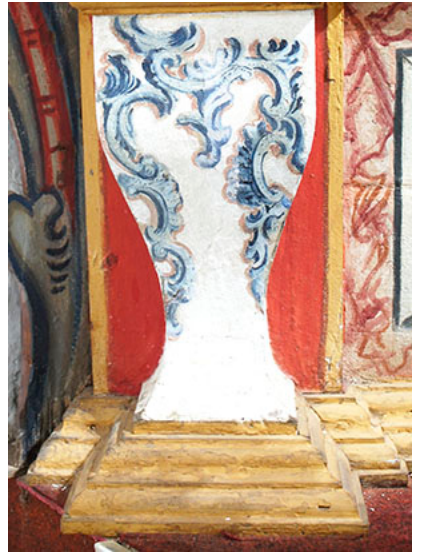

Fig. 26 Rocallas localizadas en los pedestales. Son de distintos tonos azules sobre fondo blanco

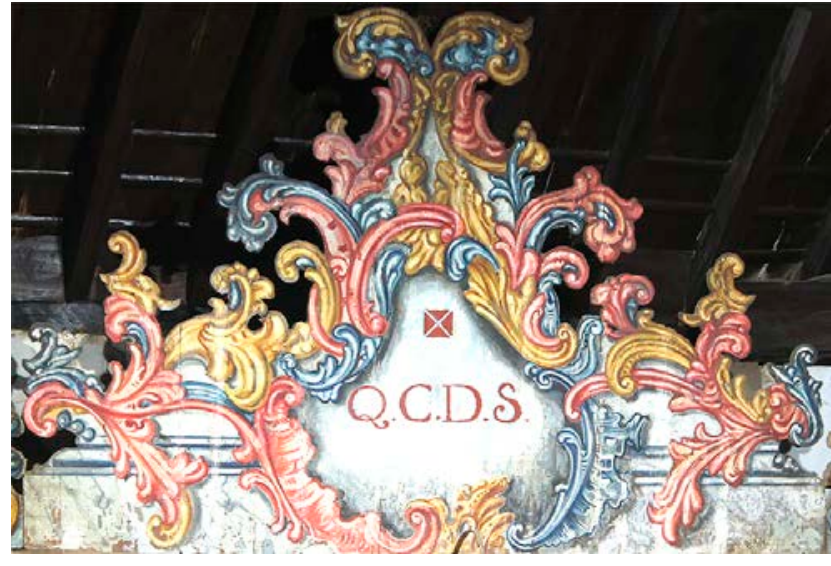

Fig. 27 Cartela de Follajes de Acanto en su parte superior y Rocallas en su parte inferior. Presenta las siglas "Q.C.D.S" -

"Quis Ut Deus/ Quien como Dios"- referidas a San Miguel

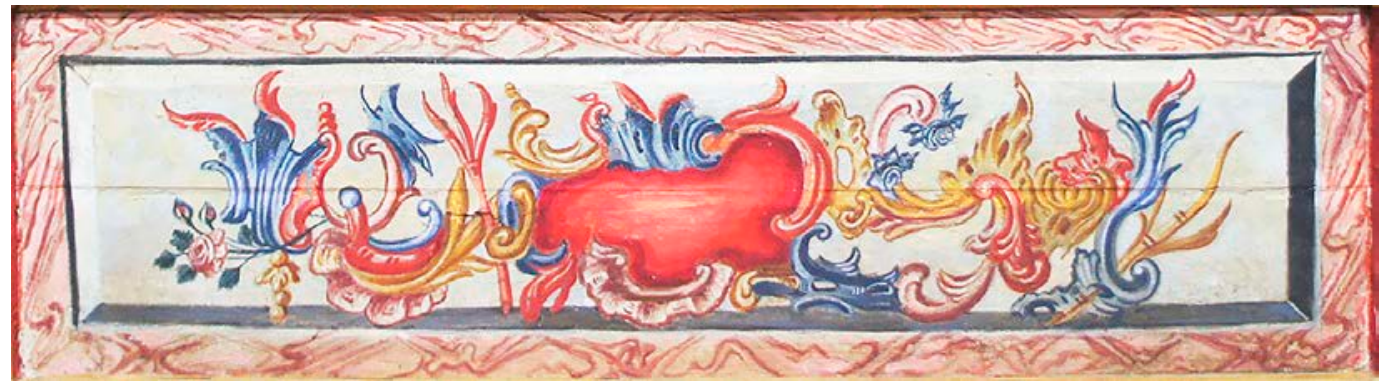

Fig. 28 Medallón en el banco de la calle central. Se encuentra acompañado de Rocallas en forma de Composiciones Asimétricas. Su dibujo cambia en cada una de las calles. También podemos observar el Jaspeado a modo de ribete y un Efecto Volumétrico mediante Planos de Color

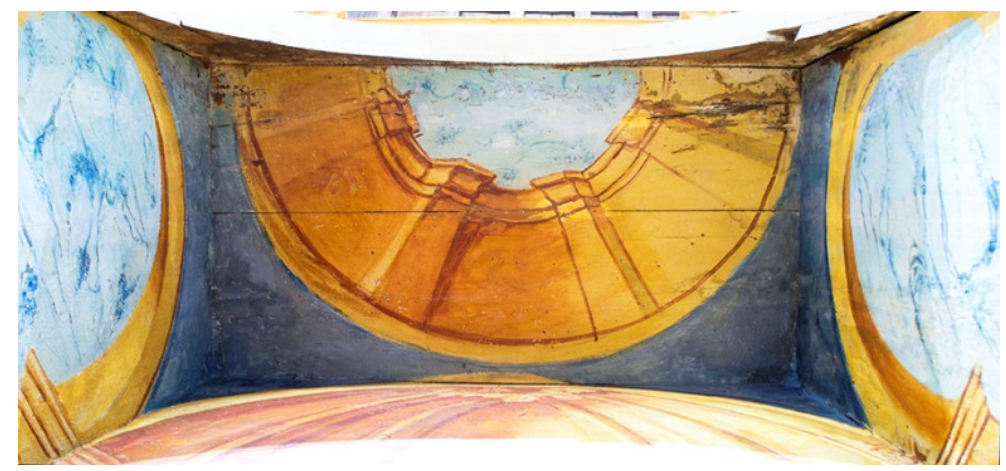

Fig. 29 Cúpula abierta al cielo mediante un óculo central, acompañado de pilastras y cornisas. Se localiza en el tablero superior de la hornacina 


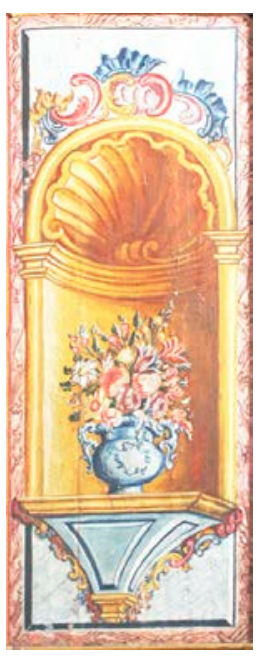

Fig. 30 Arquitecturas ilusorias presentes en la calle del lado del Evangelio. Consisten en unas hornacinas con peanas que sustentan unos jarrones con flores y que se encuentran rematadas por una bóveda en forma de concha en su parte superior. Los jarrones con flores podrían ser una tipología más de los Motivos Florales, pero, en este caso, lo consideramos un elemento más del conjunto de esta temática

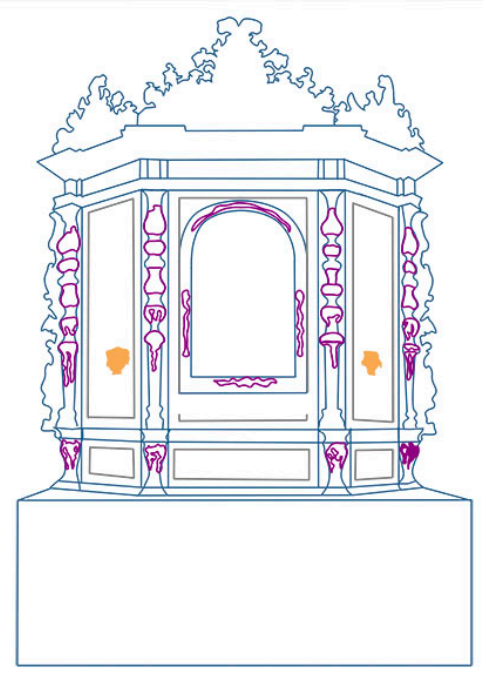

\section{Temática: Efectos Volumétricos}

Denominación: Sombreados

Lineas

Fundidos de color

Planos de color

Gráfico 3 Distribución de los Efectos Volumétricos, Denominación y Tipologías Formales

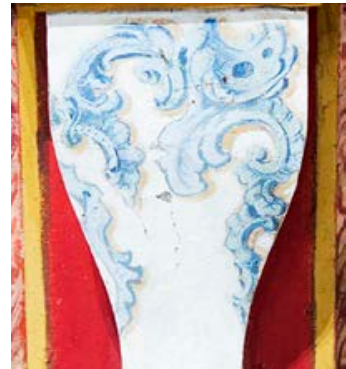

Fig. 32 Se aprecia en otro color, el uso de la Línea utilizada como sombra arrojada. Los localizamos en las rocallas localizadas en los pedestales

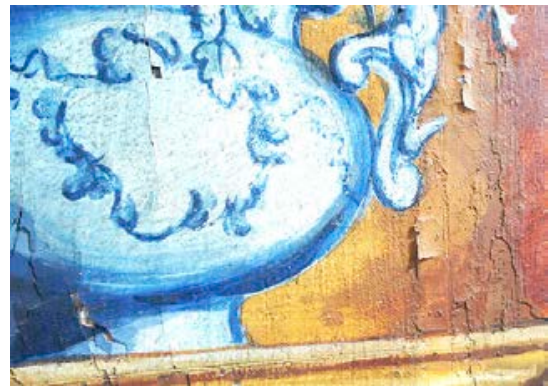

Fig. 33 Fundidos de colores consistentes en la gradación suave de tonos azules para crear volumen y realzar así, algunas partes del jarrón 


\section{Suárez Benítez}

\section{Conclusiones}

El itinerario cultural propuesto, permite acercar y divulgar el Patrimonio retablístico rococó -finales de S.XVIII- de propiedad eclesiástica de la Villa de La Orotava. Este estudio forma parte de un trabajo de investigación -Tesis Doctoral- en el que se analiza la policromía de los retablos de este periodo y que se viene realizando en la Universidad de La Laguna.

Su importancia radica en ser el primero de esta índole que se realiza en la retablística orotavense, ya que, era necesario actualizar las investigaciones de estas arquitecturas con aspectos de interés reciente y desde el enfoque de los Restauradores/as. De esta manera, se contribuye a su puesta en valor, propiciando estudios futuros desde el punto de vista técnico, para la puesta en valor de un Patrimonio de importancia histórica, artística y cultural.

\section{Referencias}

Arbelo García, A. (2005). La burguesía agraria del Valle de La Orotava (1750 - 1823). Santa Cruz de Tenerife: Thesaurus.

Bartolomé García, F. R. (2001). La policromía barroca en Álava (Tesis doctoral). Dpto. de Cultura, Diputación Foral de Álava.

Foro-ciudad. Consultada en 30 de octubre de 2019 desde https://www.foro-ciudad.com/tenerife/la-orotava/habitantes.html

La Orotava. Consultada el 30 de octubre de 2019 desde https://www.laorotava.es/es/turismo/descubre-la-orotava/conoce-su-historia.

Lorenzo Lima, J. A. (2008). El Legado del Farrobo. Bienes patrimoniales de la Parroquia de San Juan Bautista, La Orotava. La Orotava: Excmo. Ayuntamiento de la Villa de La Orotava.

Luque Hernández, A. (1998). La Orotava, corazón de Tenerife. La Orotava: Excmo. Ayuntamiento de la Villa de La Orotava.

Tenerife. Consultada el 30 de octubre de 2019 desde https://www.webtenerife.com/tenerife/la-isla/municipios/orotava/?tab=1.

Trujillo Rodríguez, A. (1977). El retablo barroco en Canarias.(Tomo I). Las Palmas de Gran Canaria: Cabildo Insular de Gran Canaria.

Tudela Noguera, M. A. (2005). El Retablo Barroco en Canarias. Tenerife siglos XVII y XVIII. Estudio tipológico: materiales y técnicas (Tesis doctoral). Tenerife: Facultad de Bellas Artes, Universidad de La Laguna. 